\title{
Comparison of motor relearning occupation-based and neurodevelopmental treatment approaches in treating patients with traumatic brain injury
}

\author{
*Jackson Nowa, BSc Hons (University of Zimbabwe). MSc OT (Wits). \\ http://orcid.org/0000-0002-1609-1520 \\ Occupational Therapist, Windhoek Central Hospital, Namibia. Postgraduate student, Department of Occupational Therapy, Dept \\ of Occupational Therapy, School of Therapeutic Sciences, Faculty of Health Sciences, University of the Witwatersrand
}

\section{Denise Franzsen, BSc OT (Wits); MSc OT (Wits; DHT (UP); PhD (Wits).} http://orcid.org/0000-000 I-8295-6329

Sessional Senior Lecturer, Dept. of Occupational Therapy, School of Therapeutic Sciences, Faculty of Health Sciences, University of the Witwatersrand.

\section{Dineo Thupae, BSc OT (UWC), MPH (Wits). https://orcid.org/0000-000 I-6470- 1333}

Lecturer, Department of Occupational Therapy, Dept of Occupational Therapy, School of Therapeutic Sciences, Faculty of Health Sciences, University of the Witwatersrand

Introduction: Traumatic Brain Injury (TBI) is caused by trauma related to motor vehicle accidents (MVAs), accidental falls and violence. Around the world, approximately 69 million people annually suffer a TBI due to various causes with the majority of cases affecting low and middle income countries (LMICS). The management of TBI requires a multidisciplinary approach which includes rehabilitation. The aim of the study was therefore to evaluate the outcomes of the Neurodevelopmental Treatment (NDT) and motor relearning occupation-based approaches on physical performance and self-care among adults with TBI.

Methods: An experimental research design comparing two groups was used in the study. The Fugl Meyer Assessment (FMA) was used to evaluate the motor performance and a Modified Barthel Index (MBI) was used to ascertain the functional independence of the study participants before and after interventions. Data were analysed using descriptive statistics and non-parametric tests.

Results: The motor relearning occupation-based approach showed greater improvement in the FMA total, upper extremity and wrist, and most of the MBI scores. The NDT approach showed greater improvement in pain scores.

Conclusion: The findings of the current study indicate that both motor relearning occupation-based and NDT treatment approaches show clinically significant improvement in physical performance and self-care. The study also shows that the motor relearning occupationbased approach is more preferable to the NDT for improvement of physical performance and self-care.

Key words: Self-care, Neurodevelopmental Treatment approach, Motor relearning occupation-based approach, Traumatic brain injury

\section{INTRODUCTION}

"Traumatic Brain Injury (TBI) is defined as an alteration in brain function, or other evidence of brain pathology caused by external forces"'. Around the world, approximately 69 million people annually suffer a TBI due to various causes. The incidence of TBI has been related to low socio-economic status, and the patterns and distribution of head injury may be specific to different geographic regions/countries with African countries having higher incidents ${ }^{2}$. This has been associated to how well preventive and safety measures related to occupational and road safety are implemented and enforced in each country ${ }^{3}$. Developing, low and middle-income countries (LMICs) report the highest prevalence of TBI affecting males at the age of 45 and below. Motor vehicle accidents (MVAs) account for the majority of these injuries due to poor enforcement of road and vehicle regulations ${ }^{2,4}$. In countries such as South Africa, Namibia, Taiwan and India, head injury resulting from MVAs is common for drivers, passengers and pedestrians ${ }^{2,5}$. The incidence of TBI resulting from MVAs in these LMICs is reported at $56 \%$, in comparison to the lower rate of $25 \%$ which occurs in the United States of America (USA) ${ }^{2}$. Although there are no prevalence figures for TBI in Namibia where this study was conducted, reported incidences of MVAs with fatalities increased by $2 \%$ in 2016 affecting the sustainable development goals which aim at reducing road deaths and injuries by $2020^{6}$.

The management of TBI and acquired brain injuries requires a multidisciplinary approach which includes rehabilitation. Rehabilitation is crucial in the mitigation of the effects of impairments, activity limitations, and participation restrictions ${ }^{7}$ during the execution of activities of daily living (ADLs), and may result in increased dependence on others and decreased quality of life (QoL). This dependence is due to deficits in higher order structures that are involved in planning and execution of smooth coordinated movements that affect the way 

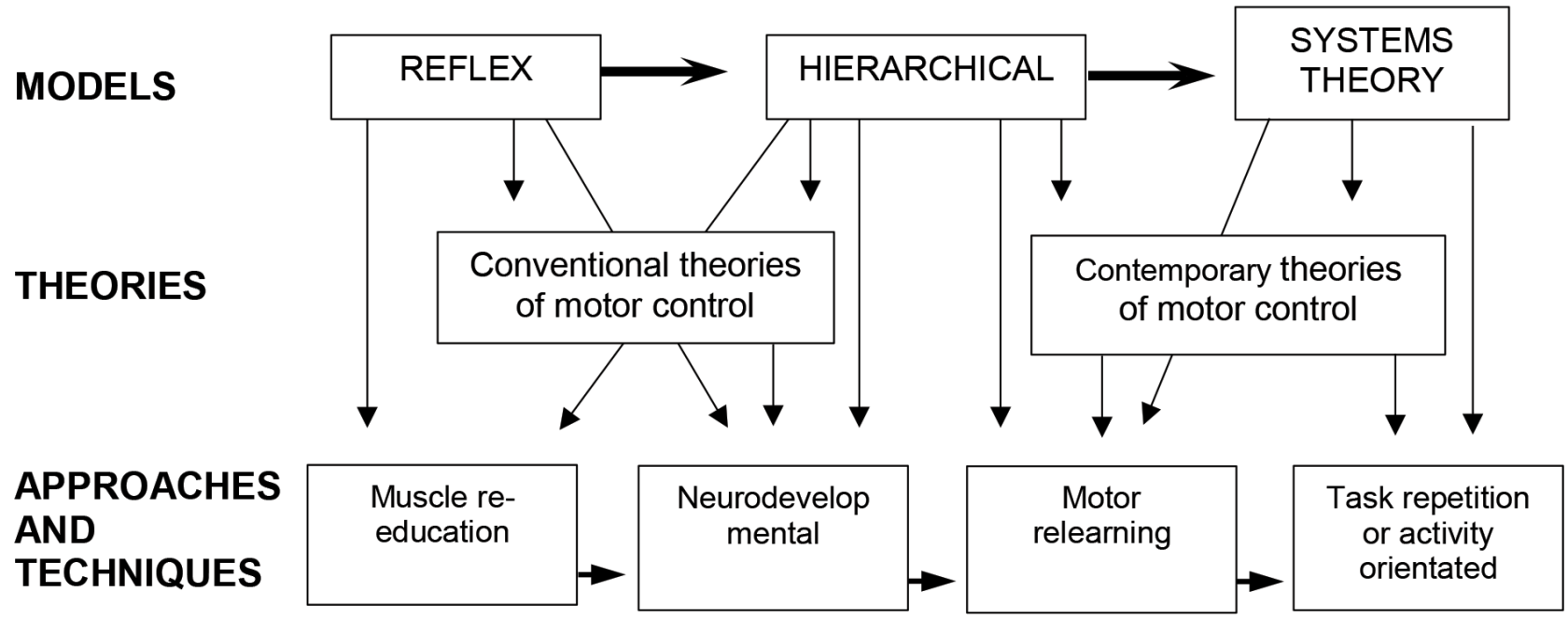

Figure I: Models and theories of motor control and their relationship to treatment approach to central nervous system (CNS) dysfunction ${ }^{22}$.

individuals execute tasks ${ }^{8,9}$. The outcomes of occupational therapy for clients with TBI include a return to performance in occupations that enable them to find meaning, increase participation and satisfy their potential in life, both in in their homes and their communities ${ }^{10}$.

Occupational Therapists working in neuro-rehabilitation use approaches and techniques based on neuroplasticity. These approaches reduce impairments and facilitate participation in activities in patients with TBI. However, the evidence that supports the efficacy of these techniques is limited and not conclusive especially in the management of TBI and the value of different treatment approaches has not been established. Occupational therapy practitioners more commonly use a bottom-up therapy by remediating specific sensory and motor deficits, based on neuro-facilitatory techniques such as the Neurodevelopmental Treatment approach $(\text { NDT })^{11,12}$. An occupation-based, or top down approach, using a motor relearning framework that considers a holistic incorporation of the patient's everyday meaningful activities has also been proposed as supporting the return to occupational performance ${ }^{12,13}$.

Therefore, the use of motor relearning occupation-based interventions and NDT approaches in the management of acute $\mathrm{TBI}$ was investigated to enable the development and synthesis of a body of knowledge in occupational therapy in order to determine the efficacy of the treatment approaches used in treating patients with TBI in a Namibian context.

\section{LITERATURE REVIEW}

A number of motor deficits manifest after an insult to the brain ${ }^{14}$ which subsequently affect the way individuals execute daily tasks ${ }^{8}$. Difficulties in mobility that are caused by problems in balance, power, coordination, and cognition are common in traumatic brain injuries ${ }^{15}$. Another devastating impairment is the loss of upper and lower extremity function (including the hand) due to paralysis/paresis ${ }^{16}$.

Motor neuro-rehabilitation is based on assumptions about the cause and nature of deficits in movement. Models which address theories of motor control related to motor learning and factors affecting motor relearning, are considered to provide the rehabilitation of motor deficits after TBI. These models and theories support the various clinical approaches, principles and techniques used by taking the concept of neuroplasticity into account ${ }^{17}$. The initial model of motor control based on the reflex theory of motor control was proposed by Sir Charles Sherrington in the I800s. It assumed that individuals require reflexes to perform movement and these reflexes are combined into actions that compose human behaviour $^{18}$. This theory of motor control does not consider centrally generated goals, or "open-loop" control, anticipatory, nor "feedforward," movements ${ }^{19}$. The hierarchical theory was consolidated based on the work of researchers in the early 1900s. It suggests that the central nervous system (CNS) is organised hierarchically with higher levels dominating and controlling the lower levels and cortical control of movement in a top-down approach throughout the central and peripheral nervous system ${ }^{17,18}$. The implications of the use of this theory clinically when treating patients with CNS damage, is that the therapist should use a developmental sequence of movements, identify and prevent primitive reflexes while normalising tone, and facilitate 'normal' movement patterns ${ }^{20}$.

The systems theory of motor control explains that the neural control over movement requires a clear understanding of body systems that are related to motion and their characteristics. This includes components of the motor programming theory of motor control and, the ecological theory developed by James Gibson in 1976 which elaborated on the interaction of the individual, the task, and the environment with the aim of eliciting a motor behaviour ${ }^{20}$. Systems theory considers the human body as a mechanical system that is subject to both internal stressors such as changes in physiological states and external stressors such as gravity. A number of movements could result from interactions between external forces and a number of commands from the system can elicit different varieties of these movements. The theory tries to elaborate on how initial conditions of a system can affect the characteristics of movement ${ }^{18}$ and it incorporates neurophysiology, biomechanics, and motor learning principles. Scott Kelso \& Tuller ${ }^{21}$ indicated that the execution of normal smooth movement is developed naturally through the practice of observable, functional occupation from a myriad of conditions and experiences. This can support techniques used in rehabilitation where environmental contexts can be modified ${ }^{17,20}$. None of the theories has proven to be better than the other in explaining the regulation of motor control and movement ${ }^{22}$.

Based on theories of motor control, different approaches and techniques are used in the rehabilitation of patients with TBI (Figure I). Most treatment approaches or neurorehabilitation protocols for motor recovery and learning are based on neuroplasticity. These neuroplasticity principles are observed after a brain injury as the 
CNS connections regenerate. This results from the development of new pathways through remapping ${ }^{23}$ and permanent changes in motor performance after continuous practice ${ }^{24}$. Treatment approaches include task-oriented approaches, neuro-facilitatory techniques, virtual reality, electrical stimulation, with the most commonly used being the NDT and motor relearning approaches ${ }^{13}$.

\section{Treatment approaches}

The NDT approach, also known as the Bobath approach, is based on the development of reflex inhibiting postures and later reflex inhibiting patterns. NDT evolved to become a problem solving NDT approach which supported the ability of a person to maintain plasticity and to learn through challenges ${ }^{24}$. The NDT approach spans all three theoretical approaches of motor control and supports the nervous system working in parallel with levels and subsystems. The basic principles of NDT include inhibitory control of abnormal movements at the same time facilitating automatic postural reactions using the therapist's hands and different techniques in goal-directed activities ${ }^{24}$. The effects of NDT on TBI patients have not yet been fully explored. Research shows the efficacy on stroke patients which might be similar for patients with TBI since both conditions are acquired neurological disorders. A study conducted by Hafsteinsdottir et $\mathrm{a}^{25}$ concluded that NDT was ineffective in the motor rehabilitation of stroke patients in the hospital setting. A systematic literature search conducted by Kollen et $\mathrm{al}^{26}$ showed that overall, this approach is not superior to alternative approaches. Díaz-Arribas et $\mathrm{al}^{27}$ showed moderate proof for greater results of alternative approaches in motor control and dexterity in the upper extremity.

The motor relearning approach (which includes the taskoriented approach and occupation-based approach) was a product of work by Carr and Shepherd ${ }^{28}$ which assumes that the brain is dynamic and capable of organising itself after injury or insult. The approach is task-oriented because it encourages the use of meaningful activities that are contextually based and incorporates active participation to achieve functional recovery and motor relearning by repetitive and intensive practice ${ }^{29}$. Although research on the effect of this approach is limited in patients with $\mathrm{TBI}$, studies show the motor relearning programme has significant effects on functional outcomes and rehabilitation of patients with stroke.

A study conducted by Chan et $\mathrm{al}^{30}$ used a matched-pair randomised control trial with 52 outpatients who suffered a cerebrovascular accident and found the motor relearning programme to be more effective in enabling functional recovery of these patients. However, they stated that both conventional and function-based activities should be implemented in neurorehabilitation. Similar findings were reported by Immadi et a $^{31}$ whose study revealed the efficacy of a repetitive task practice motor relearning programme compared to other conventional physiotherapy treatments.

Research which compared the effect of a motor relearning and NDT approach on patients with stroke by Langhammer and Stanghelle ${ }^{32}$ indicated that patients who received motor relearning therapy had early hospital discharge, with greater improvement in motor function and ADLs than those treated with NDT. Chan et $\mathrm{al}^{30}$ agree that patients treated three months' post-stroke with the motor relearning strategies have more favourable outcomes in selfcare and execution of ADLs and they showed a better transfer of skills learned to other occupations. However, the intervention did not have an effect on balance, speed or outdoor mobility ${ }^{30}$. A study by Krutulyte et $\mathrm{al}^{133}$ on 240 participants who have suffered a stroke, showed that task-oriented therapy in a motor relearning programme was preferred, but there is not enough evidence supporting the use of this approach over the others ${ }^{26}$. A Cochrane review which covered four studies on the motor relearning approach indicated that interventions did not show a higher significant clinical effectiveness from other conventional neurorehabilitation approaches ${ }^{34}$.

Evidence of the efficacy of the approaches used in occupational therapy to improve treatment outcomes and provide treatment programmes that are cost-effective and have positive effects on occupational performance is therefore required.

\section{AIM OF THE STUDY}

This study determined the outcomes of the NDT and motor relearning occupation-based approach on physical performance and self-care among adults post-acute $\mathrm{TBI}$ and compared the results of the two approaches in a Namibian setting.

\section{METHODS}

An experimental research design, comparing two groups with a pretest-posttest assessment was used in the study ${ }^{35}$. This is a design with two treatment groups were participants were assigned randomly to the groups, to consider the difference in treatment approaches on each group's participants. ${ }^{36}$. No control group was included as all participants with TBI were receiving treatment using either a motor relearning occupation-based or NDT approach. Pretest-posttest study designs are mostly used with experimental research designs because they are useful in assessing change in variables over time which can be used to compare two or more groups. The difference between interventions can be used to compare the effectiveness of treatment approaches.

The participants were recruited from the Katutura Intermediate Hospital in Windhoek, a tertiary institution which serves as a referral hospital for all the regions in Namibia. The hospital has an 880-bed capacity, and the occupational therapy department caters to most of the wards including the neurology and internal medicine wards to which patients with TBI are admitted. The patients from these wards usually spend 12 weeks on average in the specialised wards to allow for their stabilisation, early intervention, and rehabilitation before discharge.

Approximately 63 patients with TBI were admitted to the hospital per month between the period November 2017 and April 20I8. Based on a difference of II points with an SD of I5 on the $\mathrm{MBI}$ between the groups, set at a significance of 0.05 and over six months, the confidence interval of 15 and a power of $80 \%$, a sample of 30 participants per group were used in the study ${ }^{32}$. Inclusion criteria used were adults aged eighteen years and above with mild to moderate TBI (GCS Score 9 - I5) with evidence of decreased level of consciousness on admission and a present Glasgow Coma Scale (GCS) of I5/I5. Patients were recruited if they had motor or sensory dysfunction in at least one limb.

\section{Instrumentation and Outcome measures}

\section{Demographic questionnaire}

The researcher developed a demographic questionnaire to determine the demographic characteristics of the study participants which assisted in the description of participants and to better understand their context for better analysis of the data. The demographic details included sex, age, level of education, marital status, occupation, cause of injury and the participants' GCS. 
Fugl Meyer Assessment of Physical Performance (FMA) The FMA is an instrument used to evaluate motor performance after a neurological lesion. It evaluates six categories of the patient; the amount of movement, pain, sensitivity, motor function of the upper limb and lower limb, balance, coordination, and speed ${ }^{37,38}$. The scale adds up to 100 points for normal movement; 66 for upper limb and 34 for lower limb ${ }^{39,40}$.

A score of 0 shows that there is no movement observed, I shows that the movement is minimal and 2 shows that a full range of movement has been achieved ${ }^{37}$. A change in the score of 4.25 to 7.25 is seen as a clinically important difference (CID). A Global Rating Scale of Change (GROC) for the FMA indicates a change of $>50 \%$ is excellent, a change of $30 \%-50 \%$ is marked, $30 \%-10 \%$ is moderate and $<10 \%$ is slight ${ }^{41}$.

\section{Modified Barthel Index (MBI)}

The modified Barthel Index is a measure of functional independence in patients who have suffered a lesion in their brains. It provides objective and quantifiable measures of a patient's functioning. The $\mathrm{MBI}$ five-point scoring system shows the level of ability in self-care and their clinical status. Items are scored from 0-15, 0-10 and 0-5, a score of 99 shows "slight dependence", a score below 90 shows "moderate dependence", a score below 60 describes "severe dependence" and a score below 20 indicates "total dependence"42.

\section{Research Procedure}

Ethical clearance to conduct the study was obtained from the Human Research Ethics Committee (HREC) at the University of Witwatersrand (ethical clearance number: MI80970). Permission to conduct the study at Katutura Intermediate Hospital was obtained from the Ministry of Health and Social Services in Namibia through the Office of the Medical Superintendents at the hospital. Patients were invited to participate in the study if they met the inclusion criteria for the study. Informed consent from the participants was sought. Family members and guardians of vulnerable participants with a cognitive ability at Rancho Los Amigos Scale Level VII and below signed informed consent on the participants' behalf.

An occupational therapist research assistant was responsible for the random assignment of participants into the two treatment groups, with 30 allocated randomly to a motor relearning occupation-based group and 30 allocated to the NDT group using a random numbers table.

Another occupational therapist performed a pre-test assessment using the FMA of physical performance and the MBI on all the patients recruited into the study. The intervention using the two approaches was carried out in the occupational therapy department where participants were seen by two different occupational therapists. Therapists treated patients in different areas and the researcher who was completing a postgraduate course in neurosciences was involved with Group I - motor relearning occupation-based approach. A second occupational therapist with a postgraduate qualification in NDT was responsible for Group 2 - NDT approach. The motor relearning occupation-based programme used in the current study involved occupation specific training in a hospital milieu according to task demands. Training of performance skills and patterns were required for the particular tasks chosen by participants. The therapists did not follow developmental sequences and progression was achieved by increasing the complexity of the task. Therapist and patients both participated in analysis and correction of the movements for completion of tasks and emphasis was placed on repetition ${ }^{43}$. The therapist in the NDT group focused on training of normal movement patterns, normal postures and isolated weight shift during movement. Emphasis was put on testing, training of response to handling, protective reactions, postural control, and equilibrium reactions without task-specific movement patterns. The guidelines employed focused on developmental sequences and movements were elicited in prone, supine, sitting, standing and walking. The therapist analysed and corrected the movements then the participants had to follow the guidelines given by the therapist. The main guidelines included influencing of spasticity, avoidance of abnormal patterns of movement and facilitation of normal movement patterns ${ }^{44}$.

Following the routine practice of the occupational therapy department, one-hour daily interventions, five days a week for a period of four weeks were implemented with each participant until 20 sessions had been recorded. Participants who were discharged continued treatment as outpatients in their respective groups until 20 sessions were completed. They were provided with transport fares to attend occupational therapy as outpatients. After 20 treatment sessions were completed, a post-test assessment was conducted by the occupational therapist who completed the pre-test assessment using the Fugl-Meyer Assessment of physical performance and the Modified Barthel Index. To prevent bias, this occupational therapist was blinded and was unaware of which therapy they were receiving ${ }^{35}$.

\section{Data Analysis}

Frequencies and measures of central tendency were analysed using descriptive statistics. Inferential statistics used were non-parametric and included the Wilcoxon and Mann Whitney $U$ test since data were ordinal and the small sample resulted in data that were not normally distributed. These statistics were used to determine within-group differences pre and post-test as well as between-group differences pre and post-test.

\section{RESULTS}

\section{Demographics}

Forty $(66.7 \%)$ participants in the study were male. The participants' ages ranged from 18 to 68 years, with most participants between the ages of 25 - 34 (48.3\%). These demographics did not differ significantly between the NDT and motor relearning occupation-based groups indicating that the groups were comparable for gender and age. In terms of educational level, more participants in the motor relearning occupation-based group had primary school education only.

The marital status of the participants revealed that the majority (50\%) were never married, and this factor differed significantly between the NDT and motor relearning occupation-based groups $(p=0.010)$ with more motor relearning occupation-based group participants cohabiting. Motor vehicle accidents accounted for the majority of participants $(65 \%)$ injury, followed by violence which contributed to $\mathrm{TBI}$ in $30 \%$ and falls which was the cause of $\mathrm{TBI}$ in $5 \%$ of the participants.

\section{Change in physical performance}

\section{Group I- Motor relearning occupation-based approach}

Upper and lower extremity

A Wilcoxon Signed Rank Test revealed a statistically significant within group increase in FMA upper extremity values for all aspects of the assessment following participation in the motor relearning group, $(\mathrm{p}<$ 
Table I: Demographic Characteristics $(n=60)$

\begin{tabular}{|c|c|c|c|c|c|}
\hline $\begin{array}{l}\text { Demographic } \\
\text { characteristics }\end{array}$ & & $\begin{array}{l}\text { Total } \\
\text { group }\end{array}$ & $\begin{array}{l}\text { Neuro- } \\
\text { developmental } \\
\text { group }\end{array}$ & $\begin{array}{l}\text { Motor relearn- } \\
\text { ing occupation- } \\
\text { based group }\end{array}$ & p value \\
\hline & & $\mathrm{n}(\%)$ & & & \\
\hline \multirow[t]{2}{*}{ Sex } & Male & $40(66.7)$ & $19(63.3)$ & $21(70.0)$ & 0.421 \\
\hline & Female & $20(33.3)$ & $\mathrm{II}(36.4)$ & $9(30.0)$ & \\
\hline \multirow{8}{*}{$\begin{array}{l}\text { Age (Years) } \\
\text { Mean Age (S.D) } \\
36.5 \\
(10.99)\end{array}$} & & & & & \\
\hline & & & & & \\
\hline & $18-24$ & $4(6.7)$ & $2(6.6)$ & $2(6.6)$ & 0.438 \\
\hline & $25-34$ & 29(48.3) & $16(53.33)$ & $13(43.33)$ & \\
\hline & $35-44$ & $15(25.0)$ & $6(19.9)$ & $9(30.1)$ & \\
\hline & $45-54$ & $8(13.3)$ & $2(6.6)$ & $6(19.9)$ & \\
\hline & $55-64$ & $3(5.0)$ & $3(9.9)$ & & \\
\hline & $65+$ & $\mathrm{I}(\mathrm{I} .7)$ & $\mathrm{I}(3.3)$ & & \\
\hline \multirow{3}{*}{$\begin{array}{l}\text { Level of } \\
\text { Education }\end{array}$} & Primary & $9(15.0)$ & $2(6.6)$ & $7(23.7)$ & 0.069 \\
\hline & Secondary & $30(50.0)$ & $19(63.4)$ & $\mathrm{II}(36.6)$ & \\
\hline & Tertiary & $2 \mathrm{I}(35.0)$ & $9(30.0)$ & $12(40.0)$ & \\
\hline \multirow[t]{4}{*}{ Marital Status } & Cohabiting & $8(13.3)$ & & $8(26.7)$ & 0.010 *** \\
\hline & $\begin{array}{l}\text { Currently } \\
\text { Married }\end{array}$ & $2 I(35.0)$ & $10(23.4)$ & II(36.6) & \\
\hline & Divorced & $\mathrm{I}(\mathrm{I} .7)$ & $\mathrm{I}(3.3)$ & & \\
\hline & $\begin{array}{l}\text { Never } \\
\text { Married }\end{array}$ & $30(50.0)$ & $19(63.3)$ & $\mathrm{II}(36.6)$ & \\
\hline \multirow[t]{5}{*}{$\begin{array}{l}\text { Current } \\
\text { Occupation }\end{array}$} & $\begin{array}{l}\text { Non-paid } \\
\text { work (e.g. } \\
\text { volunteer) }\end{array}$ & $\mathrm{I}(\mathrm{I} .7)$ & & $\mathrm{I}(3.3)$ & 0.433 \\
\hline & $\begin{array}{l}\text { Paid } \\
\text { Employment }\end{array}$ & $34(56.7)$ & $19(63.4)$ & $15(50.0)$ & \\
\hline & $\begin{array}{l}\text { Self } \\
\text { Employed }\end{array}$ & $9(15.0)$ & $3(10)$ & $6(19.9)$ & \\
\hline & Student & $4(6.7)$ & $\mathrm{I}(3.3)$ & $3(10)$ & \\
\hline & Unemployed & I2(20.0) & $7(23.4)$ & $5(15.0)$ & \\
\hline
\end{tabular}

Significant at $\mathrm{p}<0.05^{*}$ Significant at $\mathrm{p}<.0 .01 *$ *

$0.00 \mathrm{I}$ ) with overall total improvement was $43.9 \%$ (Table II, p45). A large effect size was found for the upper extremity, the wrist and the hand (indicating a clinical difference in movement) well as sensation and pain. Coordination values showed a medium effect size even though the median value did not change since 12 participants did show improvement. In the lower extremity, the within group increase in FMA values were all statistically significant $(p<0.00 \mathrm{I})$, with a large to medium effect sizes and a $35.2 \%$ increase in the total score.

\section{Group 2 -Neurodevelopmental treatment approach} Upper and lower extremity

A statistically significant within group increase in FMA upper extremity, wrist and hand as well as all other values following participation in NDT group, $(p<0.001)$, with a large or medium effect size. A $37.8 \%$ improvement in the total score was found. A similar statistically significant increase $(p \leq 0.00 \mathrm{I})$ in all FMA lower extremity values with a total improvement of $38.3 \%$, with large to medium effect sizes with a total improvement of $38.3 \%$ was observed for this group.

All components for both groups except coordination and passive joint motion for Group 2- NDT approach participants, achieved the reported minimal clinically important difference (MCID) for the FMA upper and lower extremity scores.

\section{Comparison of between- group change in physical performance}

\section{Upper extremity}

The results on the Mann Whitney $U$ test showed a significant statistical difference in total scores for Group I - motor relearning occupation-based approach participants and Group 2 NDT approach participants, $(p=0.020)$, with a large effect size. The difference in the scores for the upper extremity $(p=0.014)$ and wrist ( $p=0.027$ ) achieved significance and the medium effect sizes indicated the difference was clinically important. There was no significant difference in the change in scores for two groups for hand, coordination, sensation and passive joint motion scores. (Table IV p46).

$A$ negative effect size and the significant difference $(p=0.010)$ for upper extremity joint pain indicated that Group 2- NDT approach participants had greater improvement than Group I motor relearning occupation-based approach participants. Improvement for both coordination and sensation scores were greater for Group 2- NDT approach participants with small and medium effect sizes. Group I motor relearning approach participants had more improvement in hand and passive joint motion scores with small effect sizes indicating little clinical significance for these results.

Lower extremity

The results for the lower extremity scores, comparing Group I motor relearning occupation-based approach participants and Group 2 NDT approach participants achieved no significant differences between the groups. Small effect sizes were found for all components when the groups were compared, with Group I motor relearning occupation-based approach participants achieving more improvement for all components.

\section{Changes in self-care}

\section{Group I Motor relearning occupation-based approach}

The findings revealed statistically significant increases in the Modified Barthel Index (MBI) for all ADL components ( $<<0.00 \mathrm{I})$, with a large effect sizes and a total improvement on the $\mathrm{MBI}$ of $78.0 \%$. (Table V, p 47) 
Table II: Group I - within group changes using a motor relearning occupation-based approach on upper and lower extremity for physical performance

\begin{tabular}{|c|c|c|c|c|c|}
\hline $\begin{array}{l}\text { Fugl Meyer Vari- } \\
\text { ables }\end{array}$ & Pre-test $(n=30)$ & Post-test $(n=30)$ & z-value & $\mathrm{p}$ value & $\begin{array}{l}\text { Effect size } \\
\text { (Cohen's r) }\end{array}$ \\
\hline & $\begin{array}{l}\text { Median (Lower and } \\
\text { upper quartile) }\end{array}$ & $\begin{array}{c}\text { Median (Lower and } \\
\text { upper quartile) }\end{array}$ & & & \\
\hline Upper extremity & $12.50(10-18)$ & $30.50(20-36)$ & -4.80 & $\leq 0.001 * *$ & $0.62 * * *$ \\
\hline Wrist & $1.50(0-5)$ & $10.00(7-10)$ & -4.83 & $\leq 0.001 * *$ & $0.62 * * *$ \\
\hline Hand & $1.00(0-6)$ & $10.00(7-12)$ & -4.79 & $\leq 0.001 * *$ & $0.62 * * *$ \\
\hline Coordination & $6.00(2-6)$ & $6.00(6-6)$ & -3.23 & $\leq 0.00 I^{* *}$ & $0.42 * *$ \\
\hline Total & $24(10-33)$ & $52.00(46-62)$ & -4.62 & $\leq 0.00$ I** & $0.60 * * *$ \\
\hline Sensation & $6.00(6-12)$ & $12.00(10-12)$ & -4.19 & $\leq 0.00 I^{* *}$ & $0.54 * * *$ \\
\hline $\begin{array}{l}\text { Passive Joint Mo- } \\
\text { tion }\end{array}$ & $16.00(10-24)$ & $20.00(20-24)$ & -3.64 & $\leq 0.001 * *$ & $0.47 * *$ \\
\hline Joint Pain & $8.00(6-10)$ & $18.00(14-20)$ & -4.74 & $\leq 0.00 I^{* *}$ & $0.61 * * *$ \\
\hline Lower Extremity & $12(8.00-16.00)$ & $24.00(20.00-26.00)$ & -4.64 & $\leq 0.00 \mathrm{I} * *$ & $0.60 * * *$ \\
\hline Coordination & $4.00(3.00-6.00)$ & $6.00(6.00-6.00)$ & -3.70 & $\leq 0.001 * *$ & $0.48 * *$ \\
\hline \begin{tabular}{|l} 
Total \\
\end{tabular} & $18(12.50-22.00)$ & $30(26.00-32.00)$ & -4.79 & $\leq 0.00 I^{* *}$ & $0.62 * * *$ \\
\hline Sensation & $6.00(6.00-12.00)$ & $12.00(12.00-12.00)$ & -3.98 & $\leq 0.00 \mathrm{I} * *$ & $0.51 * * *$ \\
\hline $\begin{array}{l}\text { Passive Joint Mo- } \\
\text { tion }\end{array}$ & $15.00(10.00-20.00)$ & $20.00(20.00-20.00)$ & $-3.7 \mid$ & $\leq 0.00$ I** & $0.48 * *$ \\
\hline Joint Pain & $10.00(7.00-10.50)$ & $20.00(18.00-20.00)$ & -4.75 & $\leq 0.00 I^{* *}$ & $0.61 * * *$ \\
\hline \multicolumn{3}{|c|}{ Significant at $p<0.05^{*}$. Significant at $p<.0 .01$ *** } & \multicolumn{3}{|c|}{$\begin{array}{l}\text { Large Effect Size }=0.5^{*} * * \\
\text { Medium Effect Size }=0.3^{*} * \\
\text { Small Effect Size }=0 . I^{*}\end{array}$} \\
\hline
\end{tabular}

Table III: Group 2 - within group changes using a neurodevelopmental treatment approach on upper and lower extremity for physical performance

\begin{tabular}{|c|c|c|c|c|c|}
\hline $\begin{array}{l}\text { Fugl Meyer } \\
\text { Variables }\end{array}$ & Pre-test $(n=30)$ & Post-test $(n=30)$ & \begin{tabular}{|l|}
$z-$ \\
value
\end{tabular} & $\mathrm{p}$ value & $\begin{array}{l}\text { Effect size } \\
\text { (Cohen's } r \text { ) }\end{array}$ \\
\hline & $\begin{array}{l}\text { Median (Lower and } \\
\text { upper quartile) }\end{array}$ & $\begin{array}{l}\text { Median (Lower and upper } \\
\text { quartile) }\end{array}$ & & & \\
\hline $\begin{array}{l}\text { Upper } \\
\text { extremity }\end{array}$ & $13.50(9.75-19.00)$ & $28.00(20.00-36.00)$ & -3.58 & $\leq 0.00 I^{*} * *$ & $0.46 * *$ \\
\hline Wrist & $3.00(0.00-5.00)$ & $7.00(5.00-10.00)$ & -4.49 & $\leq 0.00 I^{* * *}$ & $0.58 * * *$ \\
\hline Hand & $2.00(0.00-7.00)$ & $10.00(6.00-14.00)$ & -4.64 & $\leq 0.00 I^{*} *$ & $0.60 * * *$ \\
\hline Coordination & $4.00(3.00-6.00)$ & $6.00(6.00-6.00)$ & -3.58 & $\leq 0.00 I^{* *}$ & $0.46 * *$ \\
\hline Total & $22.5(12.75-33.5)$ & $49(38.75-63.75)$ & -4.79 & $\leq 0.001 * *$ & 0.62 **** \\
\hline Sensation & $6.00(6.00-12.00)$ & $12.00(10.00-12.00)$ & -4.06 & $\leq 0.00 I^{* *}$ & $0.54 * * *$ \\
\hline $\begin{array}{l}\text { Passive Joint } \\
\text { Motion }\end{array}$ & $\begin{array}{l}20.00(12.00- \\
24.00)\end{array}$ & $24.00(20.00-24.00)$ & -3.53 & $\leq 0.00 I^{* *}$ & $0.46 * *$ \\
\hline Joint Pain & $8.00(0.00-12.00)$ & $20.00(17.25-24.00)$ & -4.65 & $\leq 0.001 * *$ & $0.60 * * *$ \\
\hline $\begin{array}{l}\text { Lower } \\
\text { extremity }\end{array}$ & $12.5(6.00-16.00)$ & $24.50(18.00-26.00)$ & $-4.7 \mid$ & $\leq 0.00 I^{*} * *$ & $0.6 I^{* * * * *}$ \\
\hline Coordination & $4.00(2.25-6.00)$ & $6.00(6.00-6.00)$ & -3.74 & $\leq 0.001 * *$ & $0.48 * *$ \\
\hline Total & $17.5(6.75-22.00)$ & $30.5(24.00-34.00)$ & -4.71 & $\leq 0.001 * *$ & $0.6 I^{* * * *}$ \\
\hline Sensation & $10.00(6.00-12.00)$ & $12.00(10.00-12.00)$ & -3.34 & $\leq 0.00 I^{* *}$ & $0.43 * *$ \\
\hline $\begin{array}{l}\text { Passive Joint } \\
\text { Motion }\end{array}$ & $\begin{array}{l}20.00(10.00- \\
20.00)\end{array}$ & $20.00(20.00-20.00)$ & -3.31 & $\leq 0.001 * *$ & $0.43 * *$ \\
\hline Joint Pain & $10.00(6.75-14.50)$ & $20.00(15.50-20.00)$ & -4.33 & $\leq 0.00 I^{* *}$ & $0.56 * * *$ \\
\hline
\end{tabular}

Significant at $\mathrm{p}<0.05^{*}$. Significant at $\mathrm{p}<.0 .01 * *$.
Group 2 - Neuro-developmental treatment approach

The findings revealed statistically significant increase in MBI for all components with a large effect sizes and a total improvement for on the $\mathrm{MBI}$ of $56 \%$ (Table VI, p47).

Overall Group I - motor relearning occupation-based approach participants achieved a score above 60 post-test which indicated moderate independence while Group 2 NDT approach participants had a score below 60 indicating severe dependence post-test.

\section{Comparison of between- group change in self-care}

There was a significant difference in the total scores for the two groups $(p=0.002)$ and a medium effect size of which indicated that the Group I motor relearning occupation-based approach participants had more improvement in self-care with a clinically important difference (Table VII p48). Group I motor relearning occupation-based approach participants had a significantly larger improvement in mobility and self-care components all with large and medium effect sizes.

\section{DISCUSSION}

The demographic details were similar to a study by Samanamalee et $\mathrm{al}^{45}$ who recorded a mean age 41.67 (SD 17.47) years and the majority of the participants being males (82\%) confirming that $\mathrm{TBI}$ is more prevalent among young adults and males in LMICs. For occupational performance outcomes however, no significant differences were found in the current study although literature has reported that pre-injury occupation, high level of education, female sex and being married make a significant contributing factor to occupational performance outcomes $^{14}$. The findings from the current study suggest that most of TBI cases were caused by vehicle-related collisions which was supported by Dewan et $\mathrm{al}^{2}$ and Agrawal et $\mathrm{al}^{43}$ who reported that MVAs are responsible for the silent epidemic of TBI, among the productive age groups in LMICs.

The results of the study indicate that there was a significant improvement in physical performance and self-care in both Group I motor relearning occupation-based approach 
Table IV: Between group comparison of treatment approaches on upper and lower extremity physical performance

\begin{tabular}{|l|l|l|l|l|}
\hline Physical Components & $\begin{array}{l}\text { Change in Motor } \\
\text { learning occupation- } \\
\text { based scores }\end{array}$ & $\begin{array}{l}\text { Change in Neurode- } \\
\text { velopmental Treat- } \\
\text { ment scores }\end{array}$ & \multicolumn{2}{|l|}{} \\
\hline & $\begin{array}{l}\text { Median (Lower and } \\
\text { upper quartile) }\end{array}$ & $\begin{array}{l}\text { Median (Lower and up- } \\
\text { per quartile) }\end{array}$ & p value & $\begin{array}{l}\text { Effect size } \\
\text { (Cohen's r) }\end{array}$ \\
\hline Upper Extremity & $16.00(14.00-18.00)$ & $13.00(8.00-16.00)$ & $0.014^{*}$ & $0.45^{*} *$ \\
\hline Wrist & $5.00(4.00-10.00)$ & $5.00(2.00-5.00)$ & $0.027^{*}$ & $0.40^{*}$ \\
\hline Hand & $7.00(5.00-9.00)$ & $7.00(4.00-8.00)$ & 0.290 & $0.19^{*}$ \\
\hline Coordination & $0.00(0.00-3.00)$ & $1.00(0.00-3.00)$ & 0.970 & -0.01 \\
\hline Total & $29.00(25.00-34.00)$ & $25.00(20.00-30.00)$ & $0.020^{*}$ & $0.42^{* *}$ \\
\hline Sensation & $4.00(0.00-6.00)$ & $4.00(0.00-6.00)$ & 0.864 & -0.03 \\
\hline Passive joint motion & $5.00(0.00-10.00)$ & $2.00(0.00-8.00)$ & 0.468 & $0.13^{*}$ \\
\hline Joint pain & $10.00(6.00-10.00)$ & $12.00(8.00-14.00)$ & $0.010 * *$ & $-0.47^{* *}$ \\
\hline Lower Extremity & $12.00(8.00-18.00)$ & $10.00(8.00-16.00)$ & 0.482 & $0.13^{*}$ \\
\hline Coordination & $2.00(0.00-3.00)$ & $1.00(0.00-3.00)$ & 0.848 & 0.02 \\
\hline Total & $12.50(8.75-19.25)$ & $13.00(8.00-19.25)$ & 0.711 & 0.05 \\
\hline Sensation & $4.00(0.00-6.00)$ & $0(0.00-4.50)$ & 0.131 & $0.20^{*}$ \\
\hline Passive joint motion & $4.00(0.00-10.00)$ & $0.00(0.00-10.00)$ & 0.862 & 0.02 \\
\hline Joint pain & $10.00(6.00-10.00)$ & $9.50(3.50-10.00)$ & 0.197 & $0.17^{*}$ \\
\hline
\end{tabular}

Significant at $p<0.05^{*}$. Significant at $p<.0 .01 * *$.

Medium Effect Size $=0.3 * *$

Small Effect Size $=0.1 *$

participants and Group 2 NDT approach participants. The percentage improvement in the physical performance of the upper extremity in Group I was greater at $43.9 \%$ compared to the lower extremity at $35.2 \%$ in the current study. The notable improvements in upper extremity as compared to lower extremity found in the current study could be attributed to the fact that occupational therapists tend to focus more on the upper extremity than the lower extremity as suggested by Rowland et al ${ }^{46}$.

The participants in the motor relearning occupation-based group were found to have a $78 \%$ improvement on the $\mathrm{MBI}$ indicating the effectiveness of this approach in self-care in adults with TBI. This was confirmed by statistically significant results and the observed effect sizes which were high, describing the high clinical importance of the approach. It appears that patients using motor relearning concepts in an occupation based programme regain function and independence by being involved in occupations they find meaningful to them since these occupations improve cortical representation of their skill sets ${ }^{47}$. Occupationbased treatments done in a hospital setup that mimic the home environment improved neuroplasticity, increased functional use of the affected upper and lower extremities, and improved occupational performance ${ }^{47}$. In the current study observations were made that participants using the motor relearning occupation-based group made more efforts in fulfilling their occupations as an end goal. This was also noted by Giuffrida et $\mathrm{al}^{48}$ who stated that a significant improvement in performance is seen more in random practice than in structured practice and a transfer of skill

In this study, the motor relearning occupationbased approach was thus found to be effective in enhancing physical performance in the upper extremity in particular and task performance after TBI. Similar findings were noted in a number of other studies on patients with stroke. Chan et $\mathrm{al}^{30}$ found that the patients' recovery was noted by significant improvement in physical ability in balance as well as for all aspects of self-care assessed by the Functional Independence Measure. Kollen et $\mathrm{al}^{26}$ also concluded that activities when used in inpatient therapy can elicit functional recovery when the activities are relatively challenging to the individual performing the task. The studies by Kollen et $\mathrm{al}^{26}$ and Chan et $\mathrm{al}^{30}$ found that $\mathrm{MBI}$ (as in the current study) showed responsiveness for improvements in transfers, bathing, personal hygiene, dressing and feeding. Although the study by Kollen et $\mathrm{al}^{26}$ provided evidence supporting the lack of superiority of the NDT approach in managing sensorimotor deficits in the upper extremity and the lower extremity as well as in execution of ADLs, in the current study there was a significant improvement in physical performance and self-care for participants in the NDT approach participants.

There are some neurological changes that is noted in the latter. are expected to occur due to a brain lesion that affect motor pathways and connections, these include loss of power, differences in tone and poor communication with the cortical areas that affect movement ${ }^{49}$. These symptoms can be addressed by using NDT which focuses mainly on the motor units and the physical performance domain assessed by the FMA showed significant improvements in upper and lower extremity total scores, sensation, coordination, movements and pain scores in the current study. The percentage improvement in the physical performance of the upper extremity in Group 2 was slightly lower at $37.8 \%$ compared to the lower extremity at $38.2 \%$ in the current study. The improvement seen in the upper and lower extremity in Group 2 was similar as therapy applies equally to both extremities since the approach supports clinical reasoning which allows the therapist to focus on individual deficits. In the current study, the therapist in the NDT group focused on training of normal movement patterns, normal postures and isolated weight shift during movement ${ }^{24}$.

No published studies on the effectiveness of NDT for adult TBI patients were sourced but Huseyinsinoglu et $\mathrm{al}^{50}$ concluded that participants treated with an NDT approach showed significant improvement in physical performance including sensorimotor function, quality and speed of movement in paretic upper extremity after stroke. They did not indicate the effect of treatment in the lower extremity. A study by Bhalerao et $\mathrm{al}^{44}$ however revealed that post-therapy participants treated with an NDT approach showed significant improvement in both upper and lower extremities on all scales of motor function and functional mobility after stroke.

The improvement seen in self-care for Group 2 participants supports the hierarchical approach in NDT that follows steps that need to be taken to achieve 
Table V: Group I - within group changes using a motor relearning occupation-based approach for self-care

\begin{tabular}{|c|c|c|c|c|c|}
\hline Barthel Index & Pre-test $(M d)(n=30)$ & Post-test (Md) $(n=30)$ & z-value & $p$ value & $\begin{array}{l}\text { Effect size } \\
\text { (Cohen's } r \text { ) }\end{array}$ \\
\hline & $\begin{array}{l}\text { Median (Lower and } \\
\text { upper quartile) }\end{array}$ & $\begin{array}{l}\text { Median (Lower and } \\
\text { upper quartile) }\end{array}$ & & & \\
\hline Chair/bed Transfers & $0.00(0.00-3.00)$ & $12.00(8.00-12.00)$ & -4.82 & $\leq 0.00 I^{* * *}$ & 0.62 **** \\
\hline Ambulation & $1.50(0.00-3.00)$ & $8.00(8.00-12.00)$ & -4.82 & $\leq 0.00 I^{* *}$ & 0.62 **** \\
\hline $\begin{array}{l}\text { Ambulation/ Wheel- } \\
\text { chair }\end{array}$ & $1.00(0.00-1.00)$ & $4.00(3.00-5.00)$ & -4.87 & $\leq 0.00 I^{* * *}$ & 0.62 **** \\
\hline Stair Climbing & $0.00(0.00-0.00)$ & $5.00(2.00-8.00)$ & -4.59 & $\leq 0.00 I^{* * *}$ & $0.59 * * *$ \\
\hline Toilet Transfers & $1.00(0.00-2.00)$ & $8.00(5.00-10.00)$ & -4.83 & $\leq 0.00 I^{* *}$ & $0.62 * * *$ \\
\hline Bowel control & $5.00(3.75-10.00)$ & $10.00(5.00-10.00)$ & -3.56 & $\leq 0.00 I^{*} *$ & $0.46 * *$ \\
\hline Bladder control & $5.00(3.75-10.00)$ & $10.00(5.00-10.00)$ & -3.56 & $\leq 0.00 I^{* * *}$ & $0.46 * *$ \\
\hline Bathing & $0.00(0.00-1.50)$ & $4.00(3.00-5.00)$ & -4.81 & $\leq 0.00 I^{*} *$ & 0.62 **** \\
\hline Dressing & $0.00(0.00-2.00)$ & $8.00(5.00-8.00)$ & -4.83 & $\leq 0.00 I^{* * *}$ & 0.62 **** \\
\hline Personal hygiene & $0.00(0.00-1.00)$ & $4.00(3.00-5.00)$ & -4.83 & $\leq 0.001 * *$ & 0.62 **** \\
\hline Feeding & $2.00(0.00-2.00)$ & $8.00(5.00-10.00)$ & -4.83 & $\leq 0.001 * *$ & $0.62 * * *$ \\
\hline Total & 2.00 & & & & \\
\hline$(10.50-34.00)$ & 80.00 & & & & \\
\hline$(59.50-86.50)$ & -4.78 & $\leq 0.001 * *$ & 0.62 **** & & \\
\hline
\end{tabular}

Significant at $\mathrm{p}<0.05^{*}$. Significant at $\mathrm{p}<.0 .01$ 粎.

Large Effect Size $=0.5^{* * *}$.

Medium Effect Size $=0.3 * *$

Small Effect Size $=0.1^{*}$

Table VI: Group 2 - within group changes using a neurodevelopmental treatment approach for self-care

\begin{tabular}{|c|c|c|c|c|c|}
\hline Barthel Index & $\begin{array}{l}\text { Pre-test (Md) } \\
(\mathrm{n}=\mathbf{3 0})\end{array}$ & $\begin{array}{l}\text { Post-test (Md) } \\
(n=30)\end{array}$ & z-value & p value & $\begin{array}{l}\text { Effect size } \\
\text { (Cohen's r) }\end{array}$ \\
\hline & $\begin{array}{l}\text { Median (Lower and } \\
\text { upper quartile) }\end{array}$ & $\begin{array}{l}\text { Median (Lower } \\
\text { and upper quartile) }\end{array}$ & & & \\
\hline Chair/bed Transfers & $0.00(0.00-3.00)$ & $8.00(3.00-12.00)$ & -4.83 & $\leq 0.001 * * *$ & $0.62 * * *$ \\
\hline Ambulation & $0.00(0.00-0.00)$ & $5.50(3.00-12.00)$ & -4.78 & $\leq 0.001 * *$ & $0.62 * * *$ \\
\hline $\begin{array}{l}\text { Ambulation/ Wheel- } \\
\text { chair }\end{array}$ & $0.00(0.00-0.00)$ & $3.50(3.00-4.00)$ & -4.86 & $\leq 0.00$ I**⿻丷木 & $0.63 * * *$ \\
\hline Stair Climbing & $0.00(0.00-0.00)$ & $2.00(0.00-2.75)$ & -4.16 & $\leq 0.00$ I** & $0.54 * * *$ \\
\hline Toilet Transfers & $0.00(0.00-0.00)$ & $5.00(2.00-8.00)$ & -4.83 & $\leq 0.00 I^{* *}$ & $0.62 * * *$ \\
\hline Bowel control & $0.00(0.00-5.00)$ & $\begin{array}{l}10.00(5.00- \\
10.00)\end{array}$ & -4.33 & $\leq 0.00 I^{* * *}$ & 0.56 **** \\
\hline Bladder control & $0.00(0.00-5.00)$ & $\begin{array}{l}10.00(5.00- \\
10.00)\end{array}$ & -4.26 & $\leq 0.001$ *** & 0.55 **** \\
\hline Bathing & $0.00(0.00-0.00)$ & $3.00(3.00-3.00)$ & -4.94 & $\leq 0.001 * *$ & $0.64 * * *$ \\
\hline Dressing & $0.00(0.00-0.00)$ & $5.00(2.00-5.00)$ & -4.87 & $\leq 0.00$ I** & $0.63 * * *$ \\
\hline Personal hygiene & $0.00(0.00-0.00)$ & $3.00(3.00-4.00)$ & -4.82 & $\leq 0.001$ *** & $0.62 * * *$ \\
\hline Feeding & $0.00(0.00-2.00)$ & $5.00(2.00-10.00)$ & -4.81 & $\leq 0.00$ I** & $0.62 * * * *$ \\
\hline Total & $2.00(0.00-12.75)$ & $\begin{array}{l}58.00(38.50- \\
72.25)\end{array}$ & -4.78 & $\leq 0.001$ 米 & $0.62 * * * *$ \\
\hline
\end{tabular}

Significant at $\mathrm{p}<0.05^{*}$. Significant at $\mathrm{p}<.0 .01$ ***
Large Effect Size $=0.5^{* * * *}$.

Medium Effect Size $=0.3 * *$

Small Effect Size $=0.1^{*}$ functional recovery by eliciting normal movements and preventing compensation ${ }^{24}$. The NDT approach is a bottomup approach which relies on treating underlying symptoms with the assumption that this will lead to an improvement in occupational performance. The findings of the current study were very different from Hafsteinsdóttir et $\mathrm{al}^{25}$ which found NDT ineffective as a treatment modality for self-care in stroke patients. It can be assumed in the current study that more emphasis was placed on self-management for participants in Group 2, since the therapist involved in the NDT programme was an occupational therapist. She may well have placed more emphasis on participation in self-care since there was a change of over $50 \%$ in the self-care assessed on the $\mathrm{MBI}$ which was higher than the change seen in the physical performance for the upper and lower extremity.

A study by Lannin and McCluskey" stated that there was no comprehensive evidence of effects of different treatment approaches used in TBI, however this was not to be mistaken for no evidence of efficacy. In the current study, between-group comparison showed that most components for both groups achieved the reported minimal clinically important difference (MCID) for the FMA upper extremity scores. Although the MCID included in the current study were recorded for stroke patients, it was assumed this could be applied to patients with $T B I$ since they are all acquired brain injuries ${ }^{5 !}$.

Overall, the change for the upper extremity was higher in Group I - motor relearning occupation-based approach participants was significantly higher with a total percentage increase of $43.9 \%$ compared to $37.8 \%$ in Group 2 - NDT approach participants. The 
Table VII: Comparison of treatment approaches on self-care

\begin{tabular}{|c|c|c|c|c|}
\hline Barthel index & $\begin{array}{l}\text { Change in } \\
\text { Motor learning } \\
\text { occupation- } \\
\text { based scores(n } \\
=30)\end{array}$ & $\begin{array}{l}\text { Change in } \\
\text { Neurodevelop- } \\
\text { mental Treat- } \\
\text { ment scores (n } \\
=30 \text { ) }\end{array}$ & p value & $\begin{array}{l}\text { Effect size } \\
\text { - Cohen's r } \\
\text { value }\end{array}$ \\
\hline & $\begin{array}{l}\text { Median (lower } \\
\text { and upper } \\
\text { quartile) }\end{array}$ & $\begin{array}{l}\text { Median (lower } \\
\text { and upper } \\
\text { quartile) }\end{array}$ & & \\
\hline $\begin{array}{l}\text { Chair/bed trans- } \\
\text { fers }\end{array}$ & $\begin{array}{l}12.00(8.00- \\
12.00)\end{array}$ & $\begin{array}{l}8.00(3.00- \\
12.00)\end{array}$ & $0.002 * *$ & $0.39 * *$ \\
\hline Ambulation & $\begin{array}{l}8.00(8.00- \\
12.00)\end{array}$ & $\begin{array}{l}5.50(3.00- \\
12.00)\end{array}$ & 0.072 & $0.23 *$ \\
\hline $\begin{array}{l}\text { Ambulation/ } \\
\text { wheelchair }\end{array}$ & $\begin{array}{l}4.00(3.00- \\
5.00)\end{array}$ & $\begin{array}{l}3.50(3.00- \\
4.00)\end{array}$ & $0.035^{*}$ & $0.28 *$ \\
\hline Stair climbing & $\begin{array}{l}5.00(2.00- \\
8.00)\end{array}$ & $2.00(0.00-2.75)$ & $0.027^{*}$ & $0.31 * *$ \\
\hline Toilet transfers & $\begin{array}{l}8.00(5.00- \\
10.00)\end{array}$ & $\begin{array}{l}5.00(2.00- \\
8.00)\end{array}$ & $0.023^{*}$ & $0.31 * *$ \\
\hline Bowel control & $\begin{array}{l}10.00(5.00- \\
10.00)\end{array}$ & $\begin{array}{l}10.00(5.00- \\
10.00)\end{array}$ & 0.413 & $0.10 *$ \\
\hline Bladder control & $\begin{array}{l}10.00(5.00- \\
10.00)\end{array}$ & $\begin{array}{l}10.00(5.00- \\
10.00)\end{array}$ & 0.364 & $0.12 *$ \\
\hline Bathing & $\begin{array}{l}4.00(3.00- \\
5.00)\end{array}$ & $\begin{array}{l}3.00(3.00- \\
3.00)\end{array}$ & $0.00 I^{*} *$ & $0.53 * * *$ \\
\hline Dressing & $\begin{array}{l}8.00(5.00- \\
8.00)\end{array}$ & $\begin{array}{l}5.00(2.00- \\
5.00)\end{array}$ & 0.001 *** & $0.43 * *$ \\
\hline $\begin{array}{l}\text { Personal Hy- } \\
\text { giene }\end{array}$ & $\begin{array}{l}4.00(3.00- \\
5.00)\end{array}$ & $\begin{array}{l}3.00(3.00- \\
4.00)\end{array}$ & $0.008^{* * *}$ & $0.34 * *$ \\
\hline Feeding & $\begin{array}{l}8.00(5.00- \\
10.00)\end{array}$ & $\begin{array}{l}5.00(2.00- \\
10.00)\end{array}$ & 0.096 & $0.22 *$ \\
\hline Total & $\begin{array}{l}80.00(59.50- \\
86.50)\end{array}$ & $\begin{array}{l}58.00(38.50- \\
72.25)\end{array}$ & 0.004 & $0.37 * *$ \\
\hline
\end{tabular}

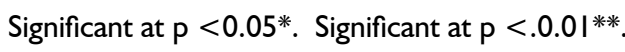

Large Effect Size $=0.5^{* * *}$.

Medium Effect Size $=0.3 * *$

Small Effect Size $=0 . I^{*}$

results from the current study are in line with a study by Langhammer and Stanghelle ${ }^{32}$ who concluded that treatment that used the motor relearning approach was preferred in improving upper extremity physical performance to the one using the NDT approach in the acute rehabilitation of stroke patients. Skubik-Peplaski et $\mathrm{al}^{47}$ also showed a significant improvement in total FMA scores in occupation-based intervention programme.

However, the current study illustrated that the change in participants in Group I was not consistently better than that for participants in Group 2. While there was significantly greater change for the upper extremity and wrist on the FMA for Group I, there was no significant difference between the two groups in hand, passive joint movement, sensation and coordination. However, the effect size favoured Group I - motor relearning occupation-based ap-
This could be attributed to the length of time for which the participants received input in the treatment approach which was not enough to cause significant changes in the client factors such as sensation. On the other hand, the participants in Group 2 - NDT approach had significantly more improvement for pain scores compared to the participants in Group I - motor relearning occupation-based approach. This is likely attributed to the use of handling and positioning that NDT focuses on, Walsh ${ }^{55}$ stated that poor positioning exacerbates shoulder pain and other types of pain in patients with stroke. This can be addressed directly when using an NDT approach.

When comparing the differences in selfcare between the groups, Group I- motor relearning occupation-based approach participants also had significantly more improvement in $\mathrm{MBI}$ scores than Group 2 - NDT approach participants. Medium to large effect sizes were found for seven of the domains of the $\mathrm{MBI}$ indicating important clinical difference for the two groups. A significant improvement noted in self-care domains was noted for Group I for ambulation/wheelchair, transfers, bathing, stair climbing, personal hygiene, dressing, and feeding when using the motor relearning occupation-based approaches. This was confirmed by the much higher percentage change in self-care assessed on the $\mathrm{MBI}$ (78\%) for participants in Group I - motor relearning occupation-based approach than the participants in Group 2 - NDT approach (56\%). This is important since Zhu et al ${ }^{56}$ have shown that self-care scores are a better predictor of recovery from moderate $\mathrm{TBI}$ at one year than age and GCS.

The results of the current study appear to support that the use of the motor relearning occupation-based approach for outcomes in physical performance in the upper limb and in self-care compared to the NDT approach. Since there was no significant difference for the lower extremity, the findings of Seneviratne and Reimer ${ }^{57}$, who concluded, when comparing the NDT and the motor relearning approach that mixed conclusions may be found was accepted. They are in agreement with some other studies that indicate that a motor relearning occupation-based approach should be added to the current occupational therapy theory and practice and this approach can be considered complimentary to NDT rather than superior to it. Therefore, the use of both approaches for various goals in occupational therapy should be considered. 


\section{Limitations}

Even though the sample size was relatively small, data gathered can be generalised to occupational therapy practice in Namibia since the results still provide meaningful findings and insights. There may have been unknown confounding variables such as the expertise that the therapists had on the treatment approaches and the motivation the clients had. It is most likely that the patients who showed improvements put in more effort than the other clients, there was no way to measure the effort put in by participants. All participants received other forms of therapy during this period and it is not clear what effect this may have had on their improvement. It is possible that some aspects of the individual therapists and the environment such as a treatment setting, ways of instruction and feedback might have led to some biases that were not controlled for in this study which might have affected the effect sizes.

\section{CONCLUSION}

The findings of the current study indicate that both motor relearning occupation-based and NDT treatment approaches are effective in occupational therapy treatment of acute traumatic brain injuries and there was a significant improvement in physical performance as well as self-care. However, the motor relearning occupationbased approach was found to be significantly superior in self-care outcomes as well as some upper extremity outcomes. No difference was found for lower extremity outcomes between the two treatment approaches. The NDT treatment approach was found to be significantly superior in addressing joint pain domains which had a significant increase compared to the other group.

\section{REFERENCES}

I. Menon DK, Schwab K, Wright DW, Maas Al. Position statement: Definition of traumatic brain injury. Archives of Physical Medicine and Rehabilitation. Elsevier Inc. 2010; 91(11): 1637-1640.

https://doi.org/10.1016/j.apmr.2010.05.017

2. Dewan MC, Rattani A, Gupta S, Baticulon RE, Hung Y-C, Maria P, et al. Estimating the global incidence of traumatic brain injury. Journal of Neurosurgery. Journal of Neurosugery. 2018; 4 (2018): 1080- 1097. https://doi.org//0.3171/2017.10.JNSI7352.

3. Zolotor AJ, Runyan DK, Shanahan M, Durrance CP, Nocera M, Sullivan $\mathrm{K}$, et al. Effectiveness of a statewide abusive head trauma prevention program in North Carolina. JAMA Pediatrics. American Medical Association. 2015; 169(12): II26-II31.

https://doi.org/10.100I/jamapediatrics.2015.2690

4. Bustamante VK, Montes S, Madrigal MDJ, Burciaga A, Martínez ME, Johnson MJ. Technology-assisted stroke rehabilitation in Mexico: A pilot randomized trial comparing traditional therapy to circuit training in a Robot/technology-assisted therapy gym. Journal of NeuroEngineering and Rehabilitation. 2016; 13(1): I-I5. https://doi.org/10.1 I86/s 12984-016-0190-I

5. Naidoo D. Traumatic brain injury: The South African landscape. South African Medical Journal. 2013; 103(9): 613-614.

https://doi.org//0.7196/SAMJ.7325

6. Motor Vehicle Accident Fund. Road crash and claims report 2016. 2016. Avaiable at: https://abrie.github.io/NamOpenData2018/raw/ mva_fund_road_crash_and_claims_report_2016.pdf (accessed 23.6.2019)

7. OTASA. Occupational Therapy Assocation of South Africa Position Statement on Rehabilitation. South African Journal of Occupational Therapy. 2017; 47(2): 53-55.

8. Walker WC, Marwitz JH, Kreutzer JS, Hart T, Novack TA. Occupa- tional Categories and Return to Work After Traumatic Brain Injury: A Multicenter Study. Archives of Physical Medicine and Rehabilitation. 2006; 87(12): 1576-1582.

https://doi.org/10.1016/j.apmr.2006.08.335

9. Powell JM, Rich TJ, Wise EK. Effectiveness of occupation-and activity-based interventions to improve everyday activities and social participation for people with traumatic brain injury: A systematic review. American Journal of Occupational Therapy. 2016; 70(3): 7003 180040pl-7003180040p9. https://doi.org// 0.50|4/ajot.2016.020909

10. Soeker MS, Pape C. The Use of the Model of Occupational SelfEfficacy for Work Retraining: A Multiple Case Study. Occupational Therapy International. 2019; 2019(Article ID 38678 I6): I-8. https://doi.org/10.1155/2019/3867816

1 I. Lannin NA, McCluskey A. A systematic review of upper limb rehabilitation for adults with traumatic brain injury. Brain Impairment. 2008; 9(3): 237-246. https://doi.org/10.1375/brim.9.3.237

12. Wolf T, Chuh J, Floyd A, Mclnnis T, K. Williams E. Effectiveness of Occupation-Based Interventions to Improve Areas of Occupation and Social Participation After Stroke: An Evidence-Based Review. American Journal of Occupational Therapy. 2015; 69(I): II. https://doi.org/10.5014/ajot.2015.012195

13. Rahja M, Jolliffe L. There is moderate evidence for the effectiveness of occupation and activity-based interventions for people with traumatic brain injury although more evidence is needed for interventions provided specifically by occupational therapists. Australian Occupational Therapy Journal. 2018; 65(I): 73-74. https://doi.org/10.1 I I I/I440-1630.12449

14. Walker WC, Pickett TC. Motor impairment after severe traumatic brain injury: A longitudinal multicenter study. Journal of Rehabilitation Research \& Development. 2007; 44(7): 975-982. https://doi.org/10.1682/JRRD.2006.12.0158

15. Katz DI, White DK, Alexander MP, Klein RB, Di AK, Dk W, et al. Recovery of Ambulation After Traumatic Brain Injury. Archives of Physical Medicine and Rehabilitation. 2004; (6): 865-869. https://doi.org/10.1016/j.apmr.2003.11.020

16. Galea M, Khan F, Amatya B, Elmalik A, Klaic M, Abbott G. Implementation of a technology-assisted programme to intensify upper limb rehabilitation in neurologically impaired participants: A prospective study. Journal of Rehabilitation Medicine. 2016; 48(6): 522-528. https://doi.org// 0.2340/I6501977-2087

17. Cano-de-la-Cuerdaa R, Molero-Sáncheza A, Carratalá-Tejadaa M, Alguacil-Diegoa I., Molina-Ruedaa F, Miangolarra-Pagea JC, et al. Theories and control models and motor learning: Clinical applications in neurorehabilitation. Neurología (English Edition). SEGO; 20I5; 30(I): 32-4I.

https://doi.org/10.1016/j.nrleng.2011.12.012

18. Shumway-Cook A, Woollacott HM. Motor Control. Translating Research into Clinical Practice. Lippincott Williams \& Wilkins; Philadelphia; 2012.

19. Horak FB. Assumptions underlying motor control for neurologic rehabilitation. In Contemporary management of motor control problems: Proceedings of the II STEP conference 199I: II-28. Alexandria, Foundation for Physical Therapy.

20. Roller ML, Lazaro RT, ByI NN, Umphred DA. Contemporary issues and theories of motor control, motor learning, and neuroplasticity. Chapter 3 in Umphred's Neurological Rehabilitation - e-Book. Lazaro RT, Reina-Guerra SG. (eds) 2013. https://doi.org/10.1016/B978-0-323-07586-2.00013-3

21. Scott Kelso JA, Tuller B. A Dynamical Basis for Action Systems. Handbook of Cognitive Neuroscienc;. 2013. 
https://doi.org/10.1007/978-1-4899-2177-2_16

22. Mathiowetz $\mathrm{V}$, Haugen JB. Motor behavior research: implications for therapeutic approaches to central nervous system dysfunction. The American Journal of Occupational Therapy. 1994; 48(4): 733-745. https://doi.org//0.5014/ajot.48.8.733

23. Chen H, Epstein J, Stern E. Neural plasticity after acquired brain injury: Evidence from functional neuroimaging. Physical Medicine and Rehabilitation. 2010; 2(I2 SUPPL): S306-S3I2. https://doi.org/10.1016/j.pmrj.2010.10.006

24. Raine S, Meadows L, Lynch-Ellerington M. Bobath concept: theory and clinical practice in neurological rehabilitation. London: John Wiley \& Sons; 2013.

25. Hafsteinsdóttir TB, Algra A, Kappelle LJ, Grypdonck MHF. Neurodevelopmental treatment after stroke: A comparative study. Journal of Neurology, Neurosurgery and Psychiatry. 2005; 76(6): 788-792. https://doi.org/10.1 I36/jnnp.2004.042267

26. Kollen BJ, Lennon S, Lyons B, Wheatley-Smith L, Scheper M, Buurke $\mathrm{JH}$, et al. The effectiveness of the Bobath concept in stroke rehabilitation what is the evidence? Stroke. 2009; 40(4: e89-e97. https://doi.org/10.1 I6I/STROKEAHA. 108.533828

27. Díaz-Arribas MJ, Martín-Casas P, Cano-de-la-Cuerda R, PlazaManzano G. Effectiveness of the Bobath concept in the treatment of stroke: a systematic review. Disability and Rehabilitation. 2019; 42(I2): 1636-1649.

https://doi.org//0.1080/09638288.2019.1590865

28. Carr HJ, Shepherd RB. Neurological Rehabilitation - Optimizing Motor Performance. London: Churchill Livingstone; $20 \mathrm{I}$ I.

29. Mulder T, Hochstenbach J. Adaptability and flexibility of the human motor system: Implications for neurological rehabilitation. Neural Plasticity. 200I. https://doi.org/10.II55/NP.200I.I3I

30. Chan DYL, Chan CCH, Au DKS. Motor relearning programme for stroke patients: a randomized controlled trial. Clinical Rehabilitation. 2006; 20(3): 191-200.

https://doi.org/10.1191/0269215506CR9300A

31. Immadi KS, Achyutha KK, Reddy A, Tatakunda PK. Effectiveness of the motor relearning approach in promotong physical function of the upper limb after a stroke. International Journal of Physiotherapy. $2015 ; 2(1): 386-390$.

https://doi.org/10.1562I/ijphy/20I5/v2il/60047

32. Langhammer B, Stanghelle JK. Bobath or motor relearning programme? A comparison of two different approaches of physiotherapy in stroke rehabilitation: A randomized controlled study. Clinical Rehabilitation. 2000; 14(4): 36I-369.

https://doi.org/10.1191/0269215500cr338oa

33. Krutulyte G, Kimtys A, Krisciunas A. The effectiveness of physical therapy methods (Bobath and motor relearning program) in rehabilitation of stroke patients. Medicina (Kaunas). 2003; 39(9): 889-895.

34. Pollock A, Baer G, Campbell P, Choo PL, Forster A, Morris J, et al. Physical rehabilitation approaches for the recovery of function and mobility following stroke. Cochrane Database of Systematic Reviews. 2014; 45(I0): 202-208.

https://doi.org//0.1002/1465 I858.CD001920.pub3

35. Kumar R. Research Methodology. A step by step guide for beginners.. 3rd Editio. London: SAGE Publications; $201 \mathrm{I}$.

36. Walker $W$. The strengths and weaknesses of research designs involving quantitative measures. Journal of Research in Nursing. 2005; I0(5): 57I-582. https://doi.org//0.1 I77//36/4096050I000505

37. Gladstone DJ, Danells CJ, Black SE. The Fugl-Meyer Assessment of Motor Recovery after Stroke: A Critical Review of Its Measurement Properties. Neurorehabilitation and Neural Repair. 2002; 16(3):
232-240. https://doi.org//0.1 I 77//5459680240 I I05 I7I

38. Fugl-Meyer A, Jaasko L, Leyman I, Olsson S, Steglind S. The Post Stroke Hemiplegic Patient. Scandinavian Journal of Rehabilitation Medicine. 1975; 7(2): |3-3|.

39. Padovani C, Valério C, Pires G, Pretti F, Ferreira C, Borin G, et al. Application of the Fugl-Meyer Assessment ( FMA ) and the Wolf Motor Function Test ( WMFT) in the recovery of upper limb function in patients after chronic stroke : a literature review. Acta Fisiatr. 20I3; 20(I): 42-49. https://doi.org// 0.5935/0I04-7795.20I30008

40. Sullivan KJ, Tilson JK, Cen SY, Rose DK, Hershberg J, Correa A, et al. Fugl-Meyer Assessment of Sensorimotor Function Standardized Training Procedure for Clinical Practice and Clinical Trials. Stroke. 20I I; 42(2): 427-32. https://doi.org/10.1 I6I/STROKEAHA.I 10.592766

4I. Page SJ, Fulk GD, Boyne P. Clinically Important Differences for the Upper-Extremity Fugl-Meyer Scale in People With Minimal to Moderate Impairment Due to Chronic Stroke. Physical Therapy. 2012; 92(6): 79I-798. https://doi.org/I0.2522/ptj.20II 0009

42. Shah S, Vanclay F, Cooper B. Improving the sensitivity of the Barthel Index for stroke rehabilitation. Journal of clinical epidemiology. 1969; 42(8): 703-709. https://doi.org/10.1016/0895-4356(89)90065-6

43. Agrawal A, Galwankar S, Kapil V, Coronado V, Basavaraju S, McGuire $\mathrm{L}$, et al. Epidemiology and clinical characteristics of traumatic brain injuries in a rural setting in Maharashtra, India. 2007-2009. International Journal of Critical IIIness and Injury Science. 2012; 2(3): 167. https://doi.org/10.4103/2229-5151.100915

44. Bhalerao G, Kulkami V, Kapoor D. Comparison of Motor Relearning Program and Bobath Approach in acute stroke rehabilitation. Journal of Orthopaedics and Rehabilitation. 20I I; I ( I): 79-88.

45. Samanamalee S, Sigera PC, De Silva AP, Thilakasiri K, Rashan A, Wadanambi $S$, et al. Traumatic brain injury (TBI) outcomes in an LMIC tertiary care centre and performance of trauma scores. BMC Anesthesiology. 2018; 18(I): 4. https://doi.org/I0.I I86/s I 287 I-017-0463-7

46. Rowland TJ, Cooke DM, Gustafsson LA. Role of occupational therapy after stroke. Annals of Indian Academy of Neurology. 2008; I I (5): 99- 107

47. Skubik-Peplaski C, Custer M, Powell E, Westgate PM, Sawaki L. Comparing Occupation-Based and Repetitive Task Practice Interventions for Optimal Stroke Recovery: A Pilot Randomized Trial. Physical \& Occupational Therapy In Geriatrics. 2017; 35(3-4): 156-168. https://doi.org/10.1080/02703 I8I.2017.1342734

48. Giuffrida CG, Demery JA, Reyes LR, Lebowitz BK, Hanlon RE. Functional Skill Learning in Men With Traumatic Brain Injury. The American Journal Of Occupational Therapy. 2009; 63(4): 398-407. https://doi.org//0.50I4/ajot.63.4.398

49. Shepherd RB. Exercise and training to optimize functional motor performance in stroke: Driving neural reorganization? Neural Plasticity. 200 I; 8(I-2): I2I-129. https://doi.org/I0.1 I 55/np.200I.I2I

50. Huseyinsinoglu BE, Ozdincler AR, Krespi Y. Bobath Concept versus constraint-induced movement therapy to improve arm functional recovery in stroke patients: A randomized controlled trial. Clinical Rehabilitation. 2012; 26(8): 705-7I5. https://doi.org/10.1177//026921551/431903

51. Hiragami S, Inoue Y, Harada K. Minimal clinically important difference for the Fugl-Meyer assessment of the upper extremity in convalescent stroke patients with moderate to severe hemiparesis. Journal of Physical Therapy Science. 2019; 31(I I): 917-921: https://doi.org/10.1589/jpts.31.917

52. Platz T, Winter T, Müller N, Pinkowski C, Eickhof C, Mauritz KH. Arm ability training for stroke and traumatic brain injury patients 
with mild arm paresis: A single-blind, randomized, controlled trial. Archives of Physical Medicine and Rehabilitation. 200I; 82(7): 96I-968. https://doi.org/10.1053/apmr.200I.23982

53. Khan F, Baguley IJ, Cameron ID. Rehabilitation after traumatic brain injury. Medical Journal of Australia. 2003; 178(6): 290-295.

54. Lamontagne ME, Gagnon C, Allaire AS, Noreau L. Effect of rehabilitation length of stay on outcomes in individuals with traumatic brain injury or spinal cord injury: a systematic review protocol. Systematic reviews. 2013; 2: Article 59. https://doi.org/10. I 186/2046-4053-2-59

55. Walsh K. Management of shoulder pain in patients with stroke. Postgraduate Medical Journal. 200 I; 77(9I2): 645-649.:

https://doi.org/10.1 I36/pmj.77.912.645

56. Zhu XL, Poon WS, Chan CCH, Chan SSH. Does intensive rehabilitation improve the functional outcome of patients with traumatic brain injury (TBI)? A randomized controlled trial. Brain Injury. 2007; 2I(7): 68I-690. https://doi.org/I0.1080/0269905070 I46894 I

57. Seneviratne C, Reimer M. Neurodevelopmental treatment stroke rehabilitation: a critique and extension for neuroscience nursing practice. Axone. 2004; 26(2): 13-20.

\section{ROLES OF AUTHORS}

Jackson Nowa is a post graduate student at the Wits University who was responsible for conceptualization of the research including connecting ideas and formulation of research goals. He was responsible for data curation including management of raw data and application of statistical analysis. He managed the investigation process including seeking different approvals from the university as well as hospitals and the ministry of Health and Social Services in Namibia, and the initial writing of the original draft and corrected versions.

Denise Franzsen was a Lead supervisor, and was responsible for supervision of the research including research planning, execution and mentorship of the post graduate student. She performed validation which involved verification of research components. She was responsible for reviewing and editing write ups, critical review, commentary and revision pre and post publication stages.

Dineo Thupae was the co-supervisor, and was responsible for supervision of the research including research planning, execution and mentorship of the post graduate student. She performed validation which involved verification of research components. She was responsible for reviewing and editing write ups, critical review, commentary and revision pre and post publication stages. 